\title{
Characteristics of Selected Lining Fabrics on the Ghanaian Market Used for Garment Construction
}

\author{
Patience Danquah Monnie ${ }^{1, *}$, Winston Yao Sappor ${ }^{2}$ \\ ${ }^{1}$ Department of Vocational and Technical Education, University of Cape Coast, Cape Coast, Ghana \\ ${ }^{2}$ Department of Family and Consumer Sciences, University of Ghana, Legon, Ghana
}

Email address:

prayfat1@yahoo.com (P. D. Monnie), winstonsappor@gmail.com (W. Y. Sappor)

${ }^{*}$ Corresponding author

\section{To cite this article:}

Patience Danquah Monnie, Winston Yao Sappor. Characteristics of Selected Lining Fabrics on the Ghanaian Market Used for Garment Construction. Science, Technology \& Public Policy. Vol. 4, No. 1, 2020, pp. 27-33. doi: 10.11648/j.stpp.20200401.15

Received: April 3, 2020; Accepted: April 20, 2020; Published: May 19, 2020

\begin{abstract}
Linings used in garment construction provide comfort for the wearer, preserve the shape of a garment and conceal constructional details thus improving both the garment's appearance and performance. The aim of this research was to assess the performance of three most patronized lining fabrics on the Ghanaian market. Three different brands of lining fabrics commonly used for garment construction were selected and labelled A, B and C. A total number of 63 specimens were used for the study. The parameters tested included weave type, thread count, weight, tensile strength, dimensional change to washing and colourfastness. The average values of the parameters tested were recorded. The results of the study showed that the performance properties of the selected lining fabrics varied. The fabric brand $\mathrm{C}$ performed best in terms of colourfastness to crocking, change in colour to washing and dimensional stability. All the evaluated lining fabric samples met standard specifications for fibre content, weave type and strength, but not weight, while some performed better in some parameters tested than others. The thread count reflected the weight and strength of the investigated samples, but not the dimensional stability. As thread count increased the weight and strength also increased. It is therefore, recommended that consumers of lining fabrics pay much attention to their selection as their performance properties vary and can affect the fashion fabrics. Further research works can be conducted where the number of lining fabric brands will be increased to help determine the compliance of manufacturers to specifications for such products.
\end{abstract}

Keywords: Lining Fabrics, Tensile Strength, Colourfastness, Dimensional Change, Garment, Construction, Ghana

\section{Introduction}

A lining is explained as a separate, however an attached inner layer of fabric used in garment construction that conceals or covers the inside constructional details of the garment [2]. They are used in various garments such as tailored ones and a garment may be fully or partially lined [8]. Linings have functional purposes in garments, they are used to give shape to a garment, provide comfort of use of the garment and cover complex constructional details and as a result help to achieve a neat and smooth look $[11,17]$. In addition, linings are used to preserve the shape of the garment, enhance the hang and comfort of the garment as it allows the garment to slide easily over other garments and also provide insulation properties [1, 11]. Furthermore, linings help the garment manufacturer to avoid time consuming seam finishes and lessens the wear and tear of the construction on the inside of the garment [8]. Fabrics used as lining are expected to enhance the appearance of the inside of the garment without distorting functionality and comfort of the garment during use and after care [17]. In addition, lining fabrics are to have the same performance properties and lifespan as the fashion fabric [2]. They present a finished appearance, protect the wearer from internal structure, add comfort to the product, or protect the fashion fabric [10]. For example, drapery linings protect expensive fashion fabrics from exposure to harmful sunlight and linings for suit jackets finish the garment's interior and make it easier to slide over shirts or blouses.

Well designed and constructed linings are likely to prolong the wear life of the garment as the lining absorbs the stress of 
the body's activities, prevents stretching and overextension of the shell fabric and inhibits hanger stress and body contact with the shell fabric $[8,11]$. In addition, linings serve as a boundary between the body and the garment, thus preventing perspiration and body oils from coming into direct contact with the fashion fabric [11]. This shows that the lining fabric is exposed to much pressure and body fluids than the fashion fabric, however they are supposed to withstand all the pressures and still be durable for the garment life. The performance of lining is extremely important in the garment industry for the achievement of good quality garments [11] and this may be due to the extensive use of lining as a support fabric in the industry. Linings are one of the most widely used support fabrics for garment construction in Ghana [12].

There are various fabrics that are suitable for use as lining fabrics such as polyester, acetate, rayon, silk, cotton and blends and may be woven or knitted $[2,8,11]$. However, the choice of lining fabric depends on a number of factors which include, the intended end use of the garment, type of fabric to be lined in terms of its weight, fibre content/method of care, type and style of the garment, type of lining (partial or complete) and how the lining will be attached as well as the performance requirements for the product (garment) [2, 8 , 11]. The performance requirements of lining fabrics include good dimensional stability, good values for pilling resistance, abrasion resistance, good tensile strength and colourfastness to various conditions of use such as washing and perspiration $[11,17]$. The fibre content and weight of the lining fabrics are also indicators to determine their performance in use and care [11]. It is noted that the weight of the lining fabric for example, influences wearing comfort, thermal comfort, drape and hand of the garment and lighter weight linings are usually selected for their support and shaping properties [11].

The foregoing discussions have showed the significance of lining in the garment industry and has indicated that to achieve quality in lined garments, the lining fabric has to be of good quality. As stated earlier, lining is one of the most widely used support fabrics for garment construction in Ghana. An observation made by the researchers showed that garment manufacturers in Ghana usually select lining fabrics without sometimes paying much attention to the effect they may have on the fashion fabric if their performance characteristics are not good. For example, an individual may line a white fashion fabric with a black lining fabric either for aesthetics or for the lack of knowledge that if the lining fabric bleeds it will stain the fashion fabric making it unusable. For instance, fashion designers in SekondiTakoradi a city in Ghana are noted for paying little or no attention to the use of support fabrics to finish or decorate apparel products [12].

However, since Ghanaian manufacturers would want to break barriers and export their products, such products should meet specific standards such as regarding lining fabrics. Meanwhile, much research has not been conducted on the performance of the lining fabrics on the Ghanaian markets which can only be established through the application of testing procedures that the garment manufacturers may not be able to carry out before they use them for garment manufacturing. This research, therefore sought to evaluate the performance properties of three most patronized lining fabric brands on the Ghanaian market. The study was guided by the following objectives;

1. Determine the weave type, thread count, weight, strength, dimensional stability, and the colourfastness of the selected lining fabrics on the Ghanaian market.

2. Compare the performance properties of the selected lining fabrics on the Ghanaian market

3. Determine whether the selected fabrics used for lining on the Ghanaian market meet required standard specifications for lining fabrics set by the Ghana Standards Authority (GSA).

It was anticipated that this study would provide documentation on the performance of lining fabrics on the Ghanaian market as there is limited documentation on this subject matter. The outcome would also inform consumer choices when it comes to choosing lining fabrics because the study assessed and compared the most patronized lining fabric brands on the Ghanaian market. The results would also spur the Ghana Standards Authority on to investigate the lining fabrics on the market. Lastly, it would serve as literature for further studies.

\section{Materials and Methods}

\subsection{Materials}

Three most commonly used lining fabric brands on the Ghanaian market were chosen based on interactions with some fabric sellers and consumers which included dressmakers and their clients in the Greater Accra region of Ghana. For the purpose of this study, all the fabric samples were of the same colour (black) to assist in holding the colour as a constant whilst the other variables are tested to provide better judgment especially of the colourfastness tests. Also black linings are usually patronized as they can match with a number of fashion fabric colours especially the African print fabrics mostly used for garment construction. The samples were labelled A, B and C. The sample labelled ' $A$ ' was indicated as cotton polyester blend with a higher percentage of polyester, ' $B$ ' was polyester poplin and ' $\mathrm{C}$ ' poplin. The meters of each sample bought from the market was 2.5 making a total of 7.5 metres. All the lining fabric brands selected are imported. The study concentrated on the properties; weave type, weight, thread count, dimensional change to washing, colourfastness and staining to washing, colourfastness to crocking and tensile strength. A total number of 63 specimens were prepared and used in the testing of the various parameters stated.

Standard soap which is a soap without optical brightener was employed for the wash tests. It is a soap used by the textile laboratory of the GSA to conduct washing tests. It was used to help keep soap a constant. 


\subsection{Methods}

The Textiles Laboratory of the Ghana Standards Authority (GSA) was where the standard tests were conducted. Before the data were collected, the specimens were conditioned for 24 hours in a relaxed state at a relative humidity of $65 \pm 2 \%$ and a temperature of $21^{\circ} \pm 1^{\circ} \mathrm{C}$ [7], for the specimens to be in a relaxed state and have the same temperature before testing for reliable results. The following performance characteristics were evaluated:

Weave type

One specimen each measuring $2.5 \mathrm{~cm}$ in the warp direction and $2.5 \mathrm{~cm}$ in the weft direction were cut from each brand of lining fabric and labelled for easy identification. To determine the weave type of each of the fabrics investigated, a magnifying glass was employed.

Mass Per Unit Area (Weight)

Textile-woven fabrics-determination of mass per unit length and mass per unit area [5], was followed. Based on that, three specimens from each sample were made using the ruler and a marker to obtain a dimension of $10 \mathrm{~cm} \times 10 \mathrm{~cm}$ each. The specimens were marked and cut out well spread apart from the selvedge. Each specimen was placed on the electronic balance and the mass was recorded. The weights were then calculated as mass/area for each specimen, and the average calculated using Microsoft Excel.

Tensile Strength

The strip test method [9] was used for testing fabric strength with the aid of a tensile testing machine (Tinius Olsen CRE H50KT). Eighteen specimens (3 each from the warp and weft directions) each measuring $30 \mathrm{~cm} \times 7 \mathrm{~cm}$ were cut from each fabric and labelled. The lengthwise direction of each specimen was frayed to obtain $30 \mathrm{~cm} \times 5 \mathrm{~cm}$ for testing. The gauge length of the tensile testing machine was $200 \mathrm{~mm}$ and the rate of extension or the speed of extension was set at $100 \mathrm{~mm} /$ minute. Force (strength) at break was recorded for each specimen in both the warp and weft directions. Maximum forces at rupture were recorded in Newton (N). The arithmetic mean of the force at rupture was then calculated for the test specimens with length parallel to the warp and separately for those with length parallel to the weft.

Thread Count

Three specimens from each sample were made using the ruler and a marker to obtain a dimension of $1 \mathrm{~cm} \times 1 \mathrm{~cm}$ each. The specimens were marked and cut out well spread apart from the selvedge. The thread counting was done manually. For each specimen, the warp threads were separated from the weft threads and then each group of threads were counted and recorded. The mean number of warp and weft threads were also determined using Microsoft Excel.

Dimensional Change to Washing

In determining the dimensional stability of samples, three specimens from each sample were prepared from the test samples by measuring $15 \mathrm{~cm}$ along the warp and $15 \mathrm{~cm}$ along the weft using a measuring ruler [4]. The warp and weft directions were indicated. Then a pair of scissors was used to cut the specimens from the sample. A threaded needle was used to stitch along $10 \mathrm{~cm} \times 10 \mathrm{~cm}$ mark on the specimens. In order to wash the specimens to determine the stability, the mass in gram of the test specimens were determined using the electronic balance. This helps to determine the quantity of soap to be used. To prepare the standard soap solution, 1L of distilled water, $5 \mathrm{~g}$ of soap and $2 \mathrm{~g}$ of sodium carbonate were well dissolved with the help of a beaker and spatula. The specimens were washed using the standard Launder-Ometer (Gyrowash 315) at a temperature of $60 \mathrm{C}$ for 30 minutes and rinsed. They were then dried on a drying rack at room temperature. The specimens were re-measured after drying and changes in dimensions were recorded. Averages and percentages were calculated using Microsoft Excel.

Colourfastness to Washing (change in colour and staining)

A specimen from each sample was prepared from the test samples by measuring and cutting $10 \mathrm{~cm} \times 10 \mathrm{~cm}$ using the measuring ruler, marker and scissors following GS ISO 105-C10. The right sides of the specimens were attached to a piece of multi-fibre of the same dimensions. For the specimens to be washed, the mass in gram of the test specimens were determined using the electronic balance so that the amount of standard soap solution needed could be determined. The standard soap solution of $1 \mathrm{~L}$ of distilled water, $3 \mathrm{~g}$ of soap and $1 \mathrm{~g}$ of sodium carbonate were dissolved with the aid of a beaker and spatula. The specimens were washed using the standard Launder-Ometer (Gyrowash 315) at a temperature of 60C for 30 minutes and rinsed. They were then dried on a drying rack at room temperature. The ISO Greyscale was used to determine colour change and staining and readings for each specimen was done three times. Averages were calculated using Microsoft Excel.

\section{Colourfastness to Crocking}

Two specimens from each sample were cut using the ruler, a marker and a pair of scissors to obtain a dimension of $5 \mathrm{~cm} \times 14 \mathrm{~cm}$ each for dry and wet rubbing. Pieces of white cotton cloths were also prepared. The crockmeter (Crockmaster ${ }^{\circledR}$ ) was used to assess colourfastness to crocking. In turns, each test specimen was fastened by means of clamps to the baseboard of the testing device so that the long direction of the specimen followed the track of the device making sure all the colours of the design were rubbed in the test process. The rubbing finger with a cylinder of $16 \pm$ $0.1 \mathrm{~mm}$ diameter was used. For both dry and wet rubbings, the conditioned white cotton rubbing cloth was placed flat over the end of the finger with weave parallel to the direction of rubbing finger. Rubbing was performed at a rate of one cycle per second, to and fro in a straight line 10 times, with a fixed downward force of $9 \pm 0.2 \mathrm{~N}$. The test cloth was removed after rubbing and was air dried.

The tested air-dried cotton rubbing cloths were assessed for staining using the grey scale for assessing staining in the colour assessment chamber. Readings were recorded and the averages determined. 


\section{Results and Discussion}

The fabric brands used for the study were cotton polyester labeled A, polyester poplin labelled B and poplin labelled C. They were all plain woven of $1 \times 1$ repeat in both directions. In terms of fibre content and weave types, all the three samples met the standard specification indicated in GS 1032: 2013. The standard states that for a fabric to qualify for use as lining, it shall be woven, from cellulosic, synthetic fibres or their blends and shall be plain, twill or satin woven. Other details on the performance attributes of the fabric samples evaluated are presented in Tables 1 to 6 . Table 1 presents information on the thread count of the tested lining samples and Table 2 provides results on the weight of the samples evaluated.
Table 1 shows that sample A had the highest numbers of warp and weft yarns $(62 \times 25)$ followed by $\mathrm{B}(41 \times 23)$ with $\mathrm{C}$ recording the least $(35 \times 16)$. The thread count of a fabric is said to determine the density of the fabric and consequently affects the weight [10]. A higher thread count number means that there are more threads fitted within the fabric and that can make a fabric stronger and resistant to shrinkage than one with less number of yarns [10]. For end-uses where durability is important such as in children's wear, active sportswear, uniforms and other similar applications higher yarn count are preferable to a lower count [14]. Lining fabrics also have to be durable as they are the fabrics that bear the most of the pressure and the agents that are likely to affect it such as sunlight and body fluids.

Table 1. Thread count of the evaluated lining fabrics.

\begin{tabular}{llll}
\hline Specimen & Number of Warp threads & Number of weft threads & Average \\
\hline A1 & 62 & 23 & $62 \times 25$ \\
A2 & 61 & 27 & \\
A3 & 64 & 25 & $41 \times 23$ \\
B1 & 41 & 21 & \\
B2 & 40 & 25 & $35 \times 16$ \\
B3 & 42 & 23 & \\
C1 & 34 & 17 & \\
C2 & 34 & 15 & 15 \\
C3 & 36 & 15 & \\
\hline
\end{tabular}

The Ghana Standards Authority's standard for woven lining fabrics [6] did not indicate the minimum and maximum values for the thread count so could not be compared. This is a property that is useful in determining lining fabrics performance and should be considered when the standard is reviewed for manufacturers of lining fabrics to comply. For instance, it is noted that the density of lining fabrics has significant influence on their sewability properties [13]. It was observed in a study on the 'sewability properties of lining fabrics' that when warp and weft densities are high, the porosity of the lining fabric decreases [13].

Table 2. Weight of lining samples evaluated.

\begin{tabular}{lllll}
\hline Specimen & $\begin{array}{l}\text { Mass } \\
(\mathbf{g})\end{array}$ & $\begin{array}{l}\text { Area } \mathbf{( 1 0 \mathbf { c m }} \\
\times \mathbf{1 0} \mathbf{c m}) \mathbf{~ m}^{\mathbf{2}}\end{array}$ & $\begin{array}{l}\text { Weight (mass/ } \\
\text { unit area) } \mathbf{g} / \mathbf{m}^{\mathbf{2}}\end{array}$ & $\begin{array}{l}\text { Average } \\
\mathbf{g} / \mathbf{m}^{\mathbf{2}}\end{array}$ \\
\hline $\mathrm{A} 1$ & 1.1832 & 0.01 & 118.32 & \\
$\mathrm{~A} 2$ & 1.1655 & 0.01 & 116.55 & 117.9 \\
$\mathrm{~A} 3$ & 1.1891 & 0.01 & 118.91 & \\
$\mathrm{~B} 1$ & 0.7788 & 0.01 & 77.88 & 77.9 \\
$\mathrm{~B} 2$ & 0.7802 & 0.01 & 78.02 & \\
$\mathrm{~B} 3$ & 0.7786 & 0.01 & 77.86 & 54.7 \\
$\mathrm{C} 1$ & 0.4890 & 0.01 & 48.90 & \\
$\mathrm{C} 2$ & 0.5985 & 0.01 & 59.85 & \\
$\mathrm{C} 3$ & 0.5526 & 0.01 & 55.26 & \\
\hline
\end{tabular}

Table 2 shows that sample A had the highest weight value followed by $\mathrm{B}$ and $\mathrm{C}$. However, the minimum weight value for lining fabrics indicated in GS 1032: 2013 is $140 \mathrm{~g} / \mathrm{m}^{2}$. The three samples evaluated had their weights below the said minimum, hence do not meet the specification. With sample A weighing $117.9 \mathrm{~g} / \mathrm{m}^{2}$ is the closest to the minimum, followed by B with $77.9 \mathrm{~g} / \mathrm{m}^{2}$ and $\mathrm{C}$ with the least value of $54.7 \mathrm{~g} / \mathrm{m}^{2}$. Fabric weight is defined as mass per unit area of a fabric [10] and knowing the weight of lining fabrics is very important so as to be sure it is not too heavy for the fashion fabric it is to be lined with. According to the GS 1032: 2013, the minimum weight for a lining fabric should be $140 \mathrm{~g} / \mathrm{m}^{2}$, however, it can be stated that the minimum value set by the standard is high and may have to be reviewed because the weight of some of the fabrics that are usually lined with such fabrics are not even up to the minimum value of weight indicated for the lining fabrics.

For instance, three African print fabrics that were accessed had weight values of $126.8 \mathrm{~g} / \mathrm{m}^{2}, 114.2 \mathrm{~g} / \mathrm{m}^{2}$ and $147.6 \mathrm{~g} / \mathrm{m}^{2}$. Therefore, using a lining fabric of $140 \mathrm{~g} / \mathrm{m}^{2}$ weight would make the garment too heavy for the wearer as well as warm looking at the nature of the weather conditions in Ghana which is a tropical zone. Usually fabric weights of 120 to 170 $\mathrm{g} / \mathrm{m}^{2}$ are medium weight and 50 to $90 \mathrm{~g} / \mathrm{m}^{2}$ are lightweight and used for purposes such as lining [14]. Weight of the lining fabrics is one of the indicators to determine their performance as it influences wearing comfort, thermal comfort, drape and hand of the garment [11]. Usually lighter weight linings are selected for their support and shaping properties [11]. These show that the weight of the lining fabrics B and C would make them suitable for use as lining for medium weight fabrics especially for garments. In determining the weight of lining fabrics, the individual should consider the type and style of garment to be lined, functionality that is casual/sporty, tailored/professional, dressy/evening as well as the warmth the lining is to provide [2]. Based on that, an individual may select a lightweight, medium weight or heavy weight lining fabrics [2].

It must however be noted that, sample A recorded the 
highest thread count and this reflected in its weight value and same is seen in the other two samples, confirming the assertion that the higher the thread count the heavier the fabric $[10,14]$.

Table 3 gives results for the dimensional stability of the evaluated samples, Table 4 provides results for colour change and staining to washing and Table 5 presents results on colourfastness to crocking. Tensile strength results is presented in Table 6.

Table 3. Dimensional change to washing of the lining fabrics evaluated.

\begin{tabular}{|c|c|c|c|c|c|c|c|c|c|c|}
\hline \multirow[t]{2}{*}{ Specimen } & \multicolumn{2}{|c|}{$\begin{array}{l}\text { Original dimension } \\
(\mathrm{cm})\end{array}$} & \multicolumn{2}{|c|}{ New dimension (cm) } & \multicolumn{2}{|c|}{ Change in dimension } & \multicolumn{2}{|c|}{$\begin{array}{l}\text { Average dimensional } \\
\text { change }\end{array}$} & \multicolumn{2}{|c|}{$\begin{array}{l}\text { Percentage }(\%) \\
\text { change in dimension }\end{array}$} \\
\hline & Warp & Weft & Warp & Weft & Warp & Weft & Warp & Weft & Warp & Weft \\
\hline A1 & 10 & 10 & 9.8 & 9.8 & -0.2 & -0.2 & \multirow{4}{*}{-0.1} & \multirow{3}{*}{-0.2} & \multirow{3}{*}{$-1 \%$} & \multirow{3}{*}{$-2 \%$} \\
\hline $\mathrm{A} 2$ & 10 & 10 & 9.8 & 9.8 & -0.2 & -0.2 & & & & \\
\hline A3 & 10 & 10 & 10 & 9.8 & 0 & -0.2 & & & & \\
\hline B1 & 10 & 10 & 9.9 & 10.1 & -0.1 & +0.1 & & \multirow{3}{*}{+0.1} & \multirow{3}{*}{$-2 \%$} & \multirow{3}{*}{$1 \%$} \\
\hline B2 & 10 & 10 & 9.8 & 10.1 & -0.2 & +0.1 & \multirow[t]{2}{*}{-0.2} & & & \\
\hline B3 & 10 & 10 & 9.8 & 10.1 & -0.2 & +0.1 & & & & \\
\hline $\mathrm{C} 1$ & 10 & 10 & 9.9 & 10 & -0.1 & 0 & \multirow{3}{*}{-0.1} & \multirow{3}{*}{0} & \multirow{3}{*}{$-1 \%$} & \multirow{3}{*}{$0 \%$} \\
\hline $\mathrm{C} 2$ & 10 & 10 & 9.9 & 9.9 & -0.1 & -0.1 & & & & \\
\hline $\mathrm{C} 3$ & 10 & 10 & 9.9 & 10 & -0.1 & 0 & & & & \\
\hline
\end{tabular}

- Indicate decrease (shrinkage) in dimension, + increase in dimension.

Dimensional stability is the ability of the fibre or fabric to resist shrinkage or stretch during use or care [3]. The results in Table 3 shows that the dimensional stability (shrinkage and expansion) in the tested lining fabrics were minimal, indicating they would perform satisfactorily during use and care. However, since the washing was carried out once, further research can be conducted where the number of washes can be increased to determine the trend of stability in the lining fabrics. Among the three brands of lining fabrics investigated, A was the only one that experienced shrinkage in both the warp and weft directions. Shrinkage and expansion were observed in brand B in the warp and weft directions respectively, whiles shrinkage and no change in dimension was seen in brand $\mathrm{C}$ in the warp and weft directions respectively. Interestingly, even though the thread count for brands $\mathrm{B}$ and $\mathrm{C}$ were low compared to $\mathrm{A}$, their dimensional stability was very good compared to A. This could be due to the differences in their fibre content and yarn linear densities. The yarn linear density was not evaluated in this study, therefore further research can be conducted to determine if there is any relationship between the two parameters (yarn linear density and dimensional stability). The dimensional stability specification was not stated in the GS 1032: 2013 and therefore comparison with the standard could not be made. However, sample $\mathrm{C}$ performed best, but from the results they are all likely to maintain their shape during use.

Table 4. Grey scale ratings for change in colour and staining of lining samples evaluated.

\begin{tabular}{llll}
\hline \multirow{2}{*}{ Grey Scale Rating } & Specimen & & C \\
\cline { 2 - 4 } & A & B & 4 \\
\hline Average Change in colour & 3 & 4 & \\
Average staining values & & & $4 / 5$ \\
Wool & 2 & 4 & 4 \\
Acrylic & 2 & $4 / 5$ & $3 / 4$ \\
Polyester & 1 & 3 & 3 \\
Nylon & $1 / 2$ & 3 & \\
\hline
\end{tabular}

\begin{tabular}{llll}
\hline \multirow{2}{*}{ Grey Scale Rating } & Specimen & \\
\cline { 2 - 4 } & A & B & C \\
\hline Cotton & 2 & $4 / 5$ & $4 / 5$ \\
Acetate & $1 / 2$ & $1 / 2$ & 2 \\
\hline
\end{tabular}

Per the GS 1032: 2013 standard, the minimum grey scale value for change in colour after washing should be 4 , however, from Table 4, it can be observed that both samples $B$ and $C$ are at the specified minimum values of 4 . Sample A with the value of 3 indicates that this lining sample is less colourfast which shows a large gap in comparison with the unwashed sample. This means sample A, may not be able to maintain its colour during use and care as it does not conform to the standard requirement for colour change. Poor colourfastness in fabrics including those for lining can affect other clothing items during washing by destroying the items appearance and wearability [16]. The additional layer of fabric provided by lining fabrics do not only offer an opaque garment, but can also enhance the colour of the fashion fabric [15]. In that same way, if the colour of the lining fabric is not fast, it can also affect the appearance of the fashion fabric.

Table 4 depicts that sample A stains the most with a very poor staining on polyester as compared to B and C. This is not surprising looking at the colour change value in Table 4. The GS 1032: 2013 standard states that, the minimum specification for grey scale ratings for staining for both polyester and cotton is $4 / 5$. This suggests that garments made from polyester or cotton and lined with sample A are likely to get stained compared to the others. Also the colour can stain other clothing articles made from wool and or polyester when washed together. In all, it can be noted that the fabric brand $\mathrm{C}$ performed well with regard to staining compared to the other two. However, the lining fabric brands $\mathrm{B}$ and $\mathrm{C}$ met the specification for staining on cotton, but not polyester and polyamide, while A did not meet any. In terms of colour change, brand $\mathrm{B}$ and $\mathrm{C}$ met the 
specification, but not $\mathrm{A}$.

Table 5. Greyscale rating for staining of cotton rubbing cloth for lining samples.

\begin{tabular}{lll}
\hline Specimen & Tested cotton rubbing cloth & Average grey scale rating \\
\hline \multirow{2}{*}{ A } & Dry & 3 \\
& Wet & $3 / 4$ \\
B & Dry & 4 \\
& Wet & $4 / 5$ \\
C & Dry & $4 / 5$ \\
& Wet & $4 / 5$ \\
\hline
\end{tabular}

Table 5 shows that samples B and C performed better than the minimum value on greyscale indicated in the GS 1032: 2013 which is 4 , hence are colourfast to rubbing. However, sample $\mathrm{A}$ is below the minimum hence is relatively not colourfast to rubbing. In all, sample C, performed very well as compared to the other two samples. Crocking occurs when the colour on the surface of a material is transferred to another material by surface contact and rubbing [10]. In some cases, dry crocking may occur, but wet crocking is more likely that is when one of the materials is wet [10]. Lining fabrics are most likely to be rubbed when used as lining in garments, therefore, colourfastness to rubbing is an important parameter which the fabrics should be able to meet the standard specification set for. A lining fabric with poor colourfastness to rubbing such as sample A, is likely to affect the fashion fabric negating its use in terms of appearance and wearabilty.

Table 6 provides the results on the tensile strength properties of the three lining fabric samples investigated.

Table 6. Tensile strength values of the lining samples evaluated.

\begin{tabular}{lllll}
\hline \multirow{2}{*}{ Sample } & \multicolumn{2}{l}{ Force at rapture (Newton) } & \multicolumn{2}{l}{$\begin{array}{l}\text { Average force at rapture } \\
\text { (Newton) }\end{array}$} \\
\cline { 2 - 5 } & Warp & Weft & Warp & Weft \\
\hline \multirow{3}{*}{ A } & 941 & 491 & & \\
& 919 & 495 & 909 & 492 \\
& 867 & 491 & & \\
B & 654 & 337 & & \\
& 655 & 352 & 646 & \\
& 629 & 333 & & \\
& 581 & 209 & & \\
C & 587 & 188 & 579 & \\
& 569 & 169 & & \\
\hline
\end{tabular}

Table 6 shows that sample A had the highest strength values in both the warp $(909 \mathrm{~N})$ and weft $(492 \mathrm{~N})$ directions followed by $\mathrm{B}$ and $\mathrm{C}$ recorded the least values among the three samples. However, the strength values recorded by all the three lining samples were above the minimum indicated in the GS 1032: 2013 which is $250 \mathrm{~N}$ for warp and $200 \mathrm{~N}$ for weft directions of the fabric. Therefore, they all met the standard specification for strength indicating they would perform satisfactorily in terms of strength during use. The results show that the fabric brand $\mathrm{A}$ is strongest and this could be due to the high thread count it recorded as seen in Table 1. The same trend is observed in both Brands B and C.
Brand $\mathrm{C}$ had the least thread count values and recorded the least strength values as well.

\section{Conclusion}

From the results of the research, it can be concluded that the performance properties of the linings on the Ghanaian market are very different even though most consumers purchase them for same uses. The samples varied in all the parameters tested. In terms of fibre content and weave types, all the samples qualified for use as lining fabrics based on the specification indicated in the standard compared with the results [6]. The lining fabric sample A had a higher thread count probably accounting for its higher density and tensile strength. However, relatively it failed all the colourfastness tests. Brand $\mathrm{C}$ performed best with regard to colourfastness although it could not meet the specifications for staining on polyester and polyamide. The thread count reflected the weight and strength of the investigated samples but not the dimensional stability. As thread count increased the weight and strength also increased. The brand $\mathrm{C}$ performed best in terms of dimensional stability in both the warp and weft directions even though it had the least numbers of threads in both the warp and weft directions. All the samples could not meet the specification for weight as stated in GS 1032: 2013. It can be noted that sample $\mathrm{A}$ is the strongest amongst the three brands investigated, but performed poorly in terms of colourfastness, which is one of the important parameters affecting consumers. Finally, all the lining fabric samples could not meet the specifications for all the parameters indicated in the GS 1032: 2013.

\section{Recommendations}

Based on the outcome of the investigation, consumers of lining fabrics are advised to pay much attention to their selection as their performance properties vary and can affect the fashion fabrics. For instance, if fabric brand A is selected for use, it is likely to affect the colour of the fashion fabric negatively. It is recommended that if there is to be a review of the standard for lining fabrics, there should be the addition of dimensional stability and thread count specifications for manufacturers to comply. In addition, for the weight value, a range can be provided rather than the block so that individuals can have different weights of lining fabrics to choose from depending on the end-use requirements of the garment or clothing article. Further research works can be conducted where the number of lining fabric brands will be increased to help determine the compliance of manufacturers to specifications for such products. It would be interesting to investigate these same fabric brands further to establish possible causes why the brand $\mathrm{C}$ with low thread count had the best dimensional stability. The Ghana Standards Authority can also investigate these fabrics on the Ghanaian market as none of the selected samples met all the standard specifications indicated especially where they are popular brands used by consumers. 


\section{References}

[1] Association of Sewing and Design Professionals (ASDP) 2008. Standards of quality. Retrieved March 26, 2020, from https://sewingprofessionals.com/2019-asdp-standards-ofquality-pdf.

[2] Baker, M. M. 2018. Lining techniques. University of Kentucky Cooperative Extension publication.

[3] Elsasser, V. H. 2010. Textiles: concepts and principles ( $3^{\text {rd }}$ ed). USA: Fairchild Publications.

[4] Ghana Standards Authority 2008. GS ISO 5077: 2008Textiles- determination of dimensional change in domestic washing and drying. Accra, Ghana: Ghana Standards Authority.

[5] Ghana Standards Authority 1977. GS ISO 3801: 1977Textiles- woven fabrics- determination of mass per unit length and mass per unit area. Accra, Ghana: Ghana Standards Authority.

[6] Ghana Standards Authority 2013. GS 1032: 2013- Textilesspecification for woven lining fabrics. Accra, Ghana: Ghana Standards Authority.

[7] Ghana Standards Authority 2005. GS ISO 139: 2005Textiles- standard atmospheres for conditioning and testing. Accra, Ghana: Ghana Standards Authority.

[8] Heaton, L. 2001. Selecting and using supportive fabrics, linings, underlinings and Interlinings. Retrieved March 26, 2020, from www2.ca.uky.edu.CT-LMH.001.PDF.
[9] International Organization for Standardization 13934-1 2013. Textiles- Tensile properties of fabrics-Part 1: Determination of maximum force and elongation at maximum force using the strip test method. Switzerland: International Organization for Standardization.

[10] Kadolph, J. S. 2007. Quality assurance for textiles and apparel $\left(2^{\text {nd }}\right.$ ed.). New York: Fairchild Publications.

[11] Kalaoglu, F., \& Meric, B. 2005. Investigation of the performance of linings. International Journal of Clothing Science and Technology, 17 (3/4): 171-178.

[12] Ntim, C. K., \& Acquaye, R. 2018. The significance of support fabrics in apparel production in Ghana. International Journal of Innovative Research and Development, 7 (7): 438 - 494.

[13] Pamuk, O., Kurtoğlu, Ö., Tama, D., \& Öndoğan, Z. 2011. Sewability properties of lining fabrics. TEKSTIL ve KONFEKSIYYN, 301-304.

[14] Pizzuto, J. J. 2012. Fabric science (10 ${ }^{\text {th }}$ ed.). New York: Fiarchild.

[15] SpandeHouse, Inc. 2019. 4 Benefits of lining garments. Retrieved March 26, 2020, from http://www.spandexhouse.com/blogs-4-benefits-of-lininggarments.

[16] Textile Machinery Network 2013. Several factors affect the colourfastness of textiles. November 5, 2015, from $\mathrm{http}: / /$ textilemachine.fangzhijixie.com/machine_1/content/?887.html.

[17] Ünal, Z. B., Ascar, E., \& Yildirim, F. 2015. Evaluating performance characteristics of lining fabrics used for children dresses. TEKSTiL ve KONFEKSiYON, 25 (4): 323-328. 